\title{
Usefulness of Self-Expandable Stent for Recanalization of Intracranial Atherosclerotic Disease: Preliminary Experience with Enterprise Stent
}

\author{
Woo Sang Jung, $\mathrm{MD}^{1}$, Sam-Soo Kim, $\mathrm{MD}^{2}$, Kyung-Yul Lee, MD, PhD³ , Sang Hyun Suh, MD, PhD \\ ${ }^{1}$ Department of Radiology, Ajou University School of Medicine, Suwon, Korea \\ ${ }^{2}$ Department of Radiology, Kangwon National University Hospital, Kangwon National University School of Medicine, Chuncheon, Korea \\ ${ }^{3}$ Department of Neurology, Gangnam Severance Hospital, Yonsei University College of Medicine, Seoul, Korea \\ ${ }^{4}$ Department of Radiology, Gangnam Severance Hospital, Yonsei University College of Medicine, Seoul, Korea
}

\begin{abstract}
Purpose: The purpose of this preliminary study is to evaluate the efficacy and safety of the Enterprise stent for intracranial atherosclerotic disease (ICAD) in patients who presented with acute stroke due to vessel steno-occlusion and in patients with symptomatic disease despite optimum medical management.
\end{abstract}

Materials and Methods: A retrospective data analysis was performed on 15 consecutive patients who were treated with Enterprise stenting for recanalization of symptomatic intracranial steno-occlusive arteries due to underlying ICAD. Their clinical and radiological data were reviewed to evaluate procedural results, periprocedural and postprocedural complications, and clinical outcome.

Results: Enterprise stents were deployed as a rescue method in 15 patients for recanalization of steno-occlusion. All patients achieved final modified thrombolysis in cerebral infarction (mTI$\mathrm{Cl}$ ) score improvement (53.3\% with a mTICl score from 0 to $2 \mathrm{~b}$ or $3,46.7 \%$ with a mTICl score from 1 to 3). Two postprocedural complications (1 symptomatic intracranial hemorrhage and 1 severe brain edema, 13.3\%) occurred among 15 patients. Among 12 patients with acute ischemic stroke (AIS), 6 patients (50\%) had improvement in their National Institute of Health Stroke Scale of more than 4 at discharge. Seven patients (58.3\%) had a good functional outcome with 3-month modified Rankin Score (mRS) $\leq 2$, and mortality occurred ( $m R S=6$ ) in 2 patients (16.7\%). None of the $10 \mathrm{AIS}$ and 3 transient ischemic attack patients experienced further ischemic events attributable to the treated steno-occlusion during the follow-up period (ranged from 4 to 36 months, median 12 months).

Conclusion: This retrospective study suggests that Enterprise stenting can effectively and safely achieve recanalization in symptomatic steno-occlusive intracranial arteries.

Key Words: Intracranial atherosclerosis; Intracranial stenting; Ischemic stroke

\section{Correspondence to: Sang Hyun Suh, MD, PhD Department of Radiology, Gangnam Severance Hospital, Yonsei University College of Medicine, 211 Eonju-ro, Gangnam-gu, Seoul 06273, Korea Tel: $+82-2-2019-3510$ \\ Fax: +82-2-3462-5472 \\ E-mail: suhsh11@yuhs.ac}

Received: January 25, 2022 Revised: February 8, 2022 Accepted: February 10, 2022
Copyright $\odot 2022$ Korean Society of Interventional Neuroradiology This is an Open Access article distributed under the terms of the Creative Commons Attribution Non-Commercial License (http://creativecommons.org/licenses/by-nc/4.0) which permits unrestricted non-commercial use, distribution, and reproduction in any medium, provided the original work is properly cited. 


\section{INTRODUCTION}

Intracranial atherosclerotic disease (ICAD) is the cause of up to $20 \%$ of acute ischemic strokes (AIS) and transient ischemic attacks (TIA), resulting in significant morbidity and mortality, and is more frequent in Asian populations (30-50\%) than in Western populations. ${ }^{1,2}$ Even with the best medical therapy, the risk of recurrent stroke remains high. ${ }^{3}$ Among patients with symptomatic ICAD who failed medical therapy, the subsequent rates of stroke or vascular death have been as high as $45 \%$ per year. ${ }^{4}$

The relative limitations of standard medical therapy to treat symptomatic intracranial large artery steno-occlusive lesions have encouraged the development of more aggressive strategies, such as intracranial percutaneous transluminal stenting, especially with Wingspan stent, which can be alternative approaches to medical therapy and even in an acute ischemic setting. ${ }^{5-12}$ However, the Wingspan system is criticized for being bulky and requiring a multi-step deployment. ${ }^{13,14}$ On the other hand, the Enterprise stent (Codman Neurovascular, Raynham, MA, USA) can show ease of deployment and improved navigability. Although intended solely for aneurysm-embolization assistance, there has been a developing interest in the possible utility of this device for salvage stroke intervention. ${ }^{15,16}$ Therefore, we tried to evaluate the efficacy and safety of the Enterprise stent for recanalization of symptomatic intracranial large artery steno-occlusion with underlying ICAD.

\section{MATERIALS AND METHODS}

\section{Patients}

This retrospective analysis was approved by the Institutional Review Board and the informed consent was waived. The patients who underwent Enterprise stenting for symptomatic intracranial large artery steno-occlusion at a Gangnam Severance hospital between January 2010 and April 2017 were screened. Diagnosis of large artery steno-occlusion with underlying ICAD was made based on typical angiographic findings with a modified thrombolysis in cerebral infarction ( $\mathrm{mTICl})$ score $(0=$ no perfusion, $1=$ penetration with minimal perfusion, $2 a=$ partial perfusion with only partial filling less than two-thirds of the entire vascular territory, $2 b=$ complete filling of all of the expected vascular territory is visualized but the filling is slower than normal, $3=$ complete perfusion) $)^{17}$ as follows: 1) severe fixed luminal narrowing with initial mTICl score 1 or 2) initial $\mathrm{mTICl}$ score 0 with evident residual severe stenosis ( $\mathrm{mTICl}$ score 1) after the intra-arterial (IA) endovascular treatment. Symptomatic patients were defined as those who presented with Als within 6 hours of symptom onset or recurrent TIA refractory to antithrombotic therapy. The antiplatelet regimen for recurrent TIA patients was a combination treatment with 100-325 mg per day of aspirin plus 75 mg per day of clopidogrel. A total of 15 patients underwent Enterprise stenting due to underlying ICAD lesion. Twelve of the 15 patients were treated due to AIS and the remaining 3 patients were treated due to recurrent TIA.

\section{Endovascular Treatment}

Endovascular treatment was attempted in all patients under local anesthesia via the right femoral artery. If indicated, an intravenous tissue-type plasminogen activator (IV-tPA) was administered before the endovascular procedure in AIS patients. For the recanalization procedure, a $6 \mathrm{~F}$ Shuttle guiding sheath (Cook Medical Inc., Bloomington, IN, USA) or 6F guiding catheter (Envoy; Codman Neurovascular) was placed in the relevant internal carotid artery (ICA) or vertebral artery. Then, a microcatheter (Prowler select plus microcatheter; Codman Neurovascular) was navigated carefully into the steno-occlusive artery over a 0.010-inch microwire (Asahi MW; Asahi Intecc, Aichi, Japan) under fluoroscopic guidance. In all patients, a self-expandable, closed-cell intracranial stent (Enterprise stent; Codman Neurovascular) was deployed for underlying ICAD during fluoroscopic control. All 15 patients underwent Enterprise stenting for severe ICAD or fixed stenosis after IA treatment failure. The Enterprise stent was available in $4.5 \mathrm{~mm}$ diameter with multiple lengths $(14,23$, 28 , and $37 \mathrm{~mm}$ ), chosen at the discretion of the operator. Delayed angiography was performed at the end of the procedure to confirm the stent patency. IA glycoprotein IIb/ Illainhibitor (tirofiban, 0.5-1.5 mg) was bolus injected in case of instant in-stent thrombosis. A closure device (Perclose; Abbott Vascular Devices, Redwood City, CA, USA) was used to seal off the femoral artery puncture. After the stent insertion procedure, all patients maintained dual antiplatelets (aspirin $100 \mathrm{mg}+$ plavix $75 \mathrm{mg}$ ) orally for at least 3 months.

\section{Outcome Measures and Follow-Up Evaluation}

We evaluated successful recanalization with pre-post procedure findings with $\mathrm{mTICI}$ scores. After the stenting procedure, all patients underwent routine brain imaging (computed 
tomography $[\mathrm{CT}]$ or magnetic resonance imaging) 24 hours after the procedure. Periprocedural complications (e.g., vessel perforation or dissection), postprocedure complications (e.g., symptomatic intracerebral hemorrhage, progressive brain edema), and any other in-hospital neurologic complications were recorded. In patients who initially had AIS, clinical outcomes were measured by the improvement of National Institute of Health Stroke Scale (NIHSS) score during hospitalization and 3-month modified Rankin Score (mRS). A good functional outcome was defined as a $m R S$ of $\leq 2$. Symptom recurrence was defined as cerebral ischemic events in the territory that Enterprise stenting was performed during the follow-up period.

\section{RESULTS}

The baseline characteristics and the clinical follow-up results are shown in Table 1. The mean age of the patients ( 9 males and 6 females) was 69.3 years (range, 53-84 years). The number of patients with known comorbidities was as follows: 2 with atrial fibrillation, 12 with hypertension, 2 with diabetes mellitus, 4 with hyperlipidemia, 4 with coronary artery occlu- sive disease. Eight patients (53.3\%) were taking antiplatelet medication before the Enterprise stenting due to their recurrent ischemic symptoms $(n=3)$ and/or comorbidities $(n=5)$. The locations of steno-occlusive lesions were as follows: distal ICA in 4, distal ICA-middle cerebral artery (MCA) in 1, MCA in 6 , distal vertebral artery in 3, and basilar artery in 1.

All patients underwent Enterprise stent deployment for underlying ICAD lesions after other techniques had already been attempted and failed. Techniques used prior to Enterprise stent deployment included IA urokinase administration ( 2 patients), stent retriever ( 6 patients), balloon angioplasty (5 patients), and failed Wingspan stent deployment (2 patients). Additional interventions performed after Enterprise stent deployment included balloon angioplasty (2 patients) and glycoprotein (GP) Illb-Illa inhibitor administration (9 patients, 0.5-1.5 mg). The use of GP Illb-llla inhibitor during the procedure was performed when restenosis was suspected after stenting, regardless of previous antiplatelet medication.

All patients achieved final $\mathrm{mTICl}$ score improvement $(53.3 \%$ with a mTICI score from 0 to $2 \mathrm{~b}$ or $3,46.7 \%$ with a mTICI score from 1 to 3). There were 2 (13.3\%) postprocedural complications after stent deployment, 1 was symptomatic parenchymal hemorrhage and 1 was progressive brain edema, which

Table 1. Lesion locations and baseline characteristics and outcomes among 15 patients

\begin{tabular}{|c|c|c|c|c|c|c|c|c|c|}
\hline No. & Location & Initial IA treatment & $\begin{array}{c}\text { Stent length } \\
(\mathrm{mm})\end{array}$ & $\begin{array}{l}\mathrm{mTICl} \\
\text { score }\end{array}$ & $\begin{array}{l}\text { Initial } \\
\text { NIHSS }\end{array}$ & $\begin{array}{c}\text { NIHSS } \\
\text { discharge }\end{array}$ & $\begin{array}{c}\text { 3-month } \\
\text { mRS }\end{array}$ & $\begin{array}{c}\text { Postprocedural } \\
\text { complication }\end{array}$ & $\begin{array}{l}\text { Follow-up } \\
\text { period (mo) }\end{array}$ \\
\hline 1 & Right distal VA & Wingspan & 37 & $1 \rightarrow 3$ & $1(\mathrm{TIA})$ & 0 & NA & No & 36 \\
\hline 2 & Right MCA, M1 & IA urokinase & 37 & $0 \rightarrow 3$ & 13 & 6 & 3 & No & 36 \\
\hline 3 & Right distal ICA & IA urokinase & 37 & $0 \rightarrow 2 b$ & 22 & NA & 6 & Progressive edema & NA \\
\hline 4 & Left distal ICA & Stent retriever & 37 & $0 \rightarrow 3$ & 21 & 21 & 4 & Symptomatic PH & 33 \\
\hline 5 & Left distal ICA-M1 & Stent retriever & 28 & $0 \rightarrow 2 b$ & 15 & 8 & 4 & No & 12 \\
\hline 6 & Left distal VA & Balloon angioplasty & 37 & $1 \rightarrow 3$ & 6 & 0 & 0 & No & 10 \\
\hline 7 & Right MCA, M1 & Wingspan & 14 & $1 \rightarrow 3$ & $6(\mathrm{TIA})$ & 0 & NA & No & 8 \\
\hline 8 & Left MCA, M1 & Stent retriever & 28 & $0 \rightarrow 3$ & 4 & 0 & 0 & No & 12 \\
\hline 9 & Right distal ICA & Stent retriever & 37 & $0 \rightarrow 3$ & 16 & 14 & 2 & No & 18 \\
\hline 10 & Basilar artery & Balloon angioplasty & 28 & $1 \rightarrow 3$ & 6 & 5 & 2 & No & 36 \\
\hline 11 & Left distal VA & Stent retriever & 37 & $0 \rightarrow 2 b$ & 20 & NA & 6 & No & NA \\
\hline 12 & Left MCA, M1 & Stent retriever & 14 & $0 \rightarrow 3$ & 3 & 3 & 1 & No & 10 \\
\hline 13 & Left MCA, M1 & Balloon angioplasty & 23 & $1 \rightarrow 3$ & $0(\mathrm{TIA})$ & 0 & NA & No & 6 \\
\hline 14 & Right distal ICA & Balloon angioplasty & 23 & $1 \rightarrow 3$ & 9 & 4 & 2 & No & 4 \\
\hline 15 & Left MCA, M1 & Balloon angioplasty & 23 & $1 \rightarrow 3$ & 16 & 8 & 2 & No & 4 \\
\hline
\end{tabular}

IA, intra-arterial; mTICI, modified thrombolysis in cerebral infarction; NIHSS, National Institutes of Health Stroke Scale; mRS, modified Rankin Scale; VA, vertebral artery; TIA, transient ischemic attack; NA, not applicable; MCA, middle cerebral artery; ICA, internal carotid artery; PH, parenchymal hemorrhage. 
led to mortality.

Among 12 AlS patients, 3 patients (25\%) within the indication time were administered intravenous $\mathrm{PPA}$. The median initial NIHSS score was 14 (range, 3-22). Six patients (50\%) had improvement in their NIHSS score of more than 4 points at discharge. Seven patients (58.3\%) had a good functional outcome with 3-month $m R S \leq 2$, and mortality occurred ( $m R S=6$ ) in 2 patients (16.7\%). None of the 10 surviving AIS patients and 3 TIA patients experienced further ischemic events attributable to the treated ICAD lesion during the follow-up period (ranged from 4 to 36 months, median 12 months). Two case examples are illustrated in Figs. 1 and 2.
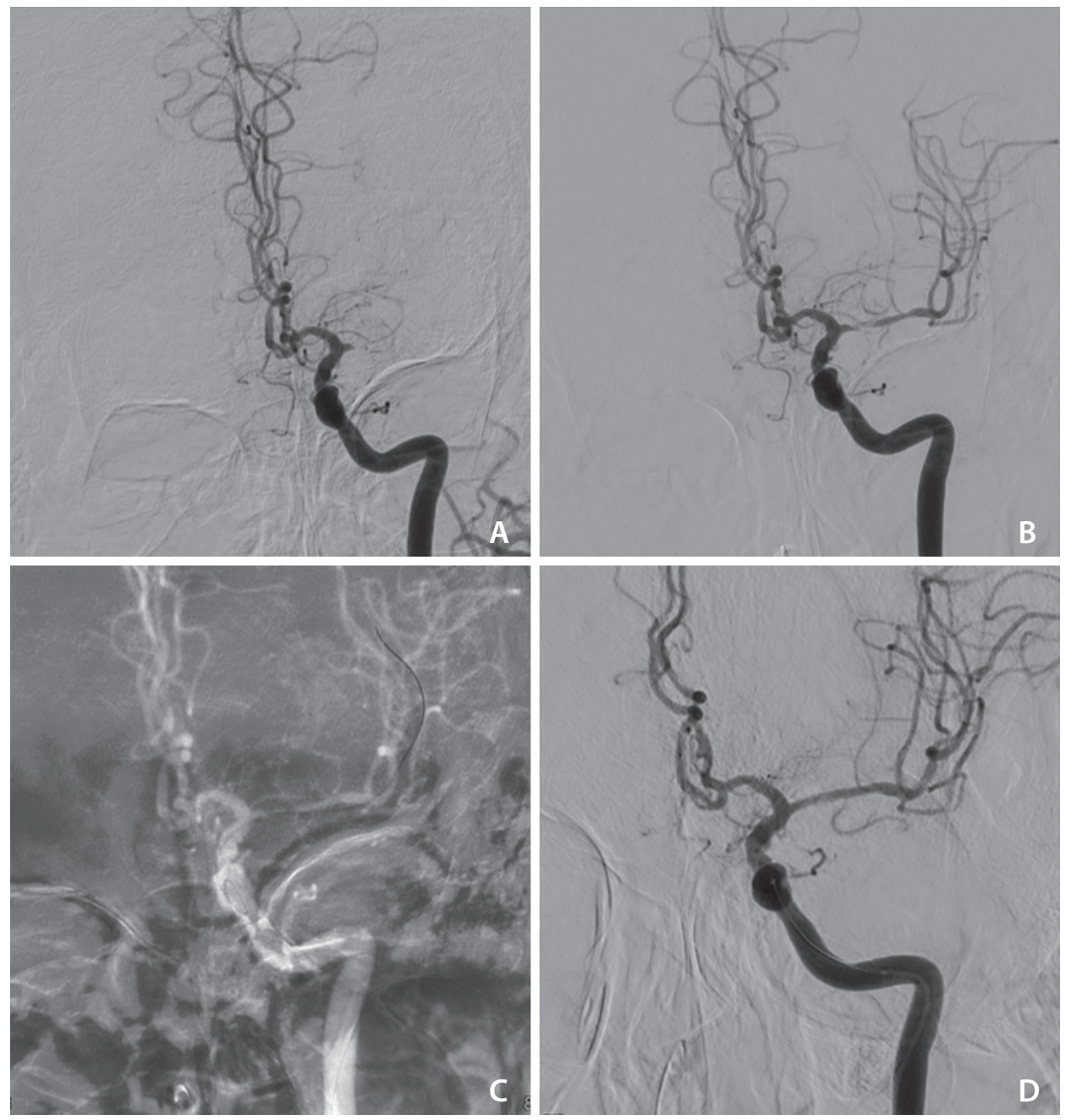

Fig. 1. An elderly patient who presented with acute left proximal MCA occlusion and NIHSS score 15. (A, B) The patient received mechanical thrombectomy initially with refractoriness due to underlying severe stenosis. (C) Enterprise stent $(28 \mathrm{~mm}$ ) was successfully deployed. (D) Fifteen minutes delayed angiography showed patent antegrade flow ( $\mathrm{mTICI}$ score 3) in the stented segment without residual stenosis. MCA, middle cerebral artery; NIHSS, National Institutes of Health Stroke Scale; mTICl, modified thrombolysis in cerebral infarction. 
reported in several studies, the Warfarin-Aspirin Symptomatic Intracranial Disease study and the Extracranial-Intracranial Bypass Study demonstrated that the results of medical or surgical management of ICAD remain far from ideal. ${ }^{23,24}$ Consequently, intracranial stenting has emerged and is increasingly being used in the USA and other countries. ${ }^{7-11,25}$ However, in 2011, the Stenting versus Aggressive Medical Therapy for Intracranial Arterial Stenosis study revealed that aggressive medical management was superior to intracranial stenting with the use of the Wingspan stent system for ICAD, because of high risk of early stroke after Wingspan stenting. ${ }^{26}$ In addition, in cases with very difficult anatomy and complex lesion geometry, the Wingspan stent system failed stent de- livery to the target lesion because of its cumbersome carrier system. ${ }^{14}$ Moreover, several studies reported sobering results with a high rate of recurrent stenosis, sometimes worse than the original lesion, and this observation raised the suspicion that the high radial force of the Wingspan stent might be a stimulus for intimal hyperplasia. ${ }^{27-29}$ However, the Enterprise stent has flexibility in delivery with a lesser radial force than the Wingspan stent, as the results with the Enterprise stent in previous studies have indicated that intracranial stenting may effective for ICAD and for primary revascularization in AIS patients. Vajda et al. ${ }^{30}$ reported satisfactory results for the treatment of symptomatic intracranial atherosclerotic stenosis with the modified Bose method using the Enterprise
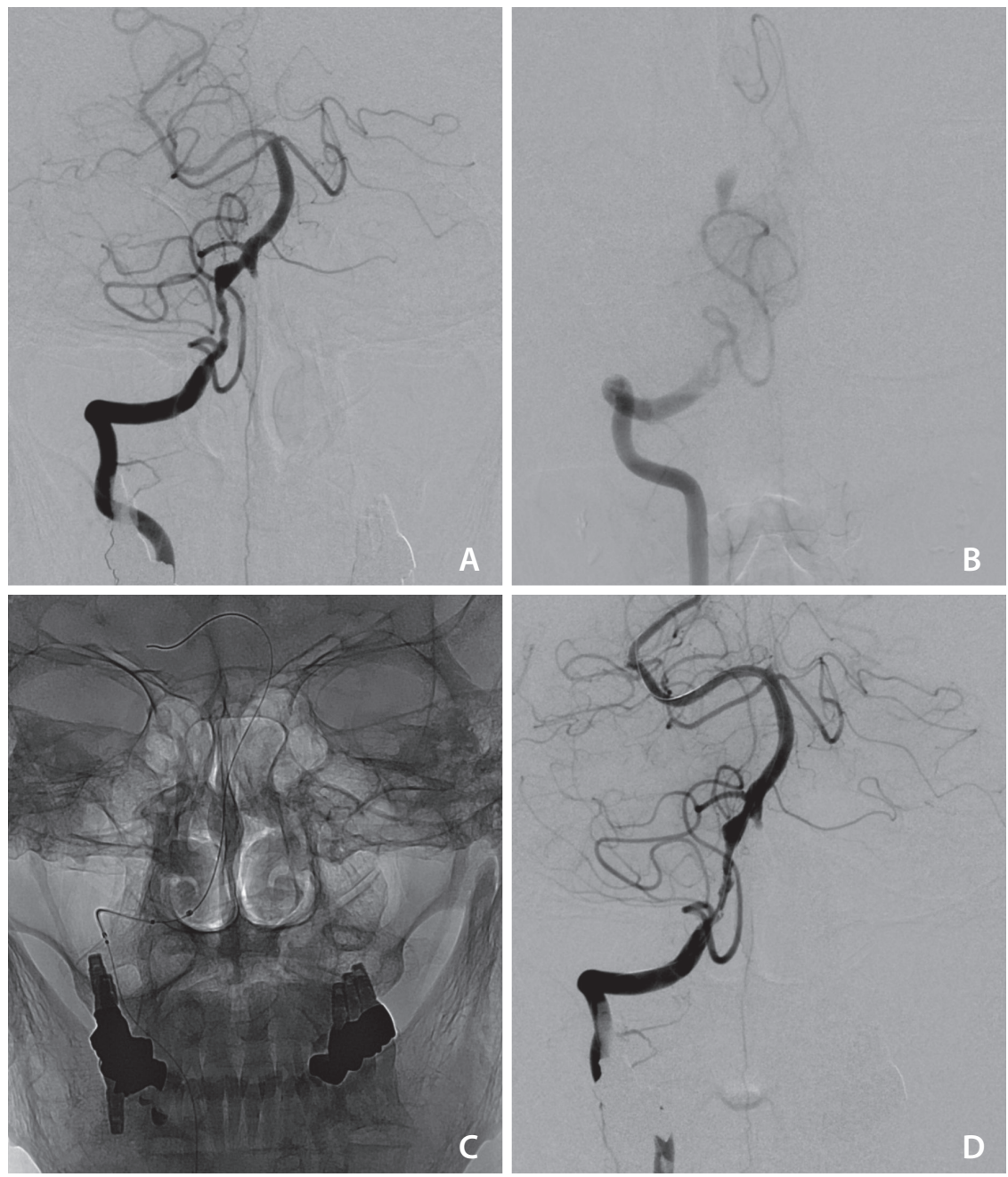

Fig. 2. An elderly patient presented with recurrent transient ischemic attack refractory to antithrombotic therapy. (A) Right vertebral angiogram showed long segment severe stenosis of the right distal vertebral artery. (B) Angiogram was performed again after 3 days due to recurred ischemic symptoms during the hospitalization. Angiogram showed mTICl score of 1 with underlying stenosis. (C) Wingspan stent system failed to pass the lesion due to underlying severe stenosis. (D) Enterprise stent was successfully deployed as a rescue method with mTICI score of 3. mTICl, modified thrombolysis in cerebral infarction. 
stent with a median pre- and postprocedural stenosis rate of $65.4 \pm 1 \%$ vs. $25.1 \pm 1 \%$ and a $100 \%$ technical success rate. In the setting of AIS, Dumont et al. ${ }^{15}$ reported that the Enterprise stent was found to be a safe and effective revascularization tool with a $90 \%$ recanalization rate and $15 \%$ major complications. In addition, Mocco et al. ${ }^{16}$ reported that 3 cases of failed Wingspan stenting were subsequently treated with successful deployment of the more navigable Enterprise stent at the occlusion site, and they suggested a potential benefit to the use of the Enterprise stent when routine intervention methods failed. However, they did not consider the underlying cause of vessel occlusion. In this study, we focused on the cause of vessel occlusion to the underlying ICAD. Although SAMMPRIS with the Wingspan stent failed to show a benefit for intracranial stenting over intensive medical management in the secondary prevention of stroke recurrence in high-risk patients with symptomatic ICAD, ${ }^{26}$ our study suggests that a high successful recanalization rate with the Enterprise stent in symptomatic patients due to underlying ICAD without stroke recurrence during the follow-up periods.

Intracranial stent placement has potential hazards, such as in-stent thrombosis, malposition of the stent, or the inability to pass the stent to the appropriate location. Kim et al. ${ }^{31}$ reported a major complication rate of 33\% with intracranial stent placement. However, in our series, we had 2 (12.5\%) periprocedural complications (1 symptomatic intracranial hemorrhage and 1 progressive brain edema) without stent malposition or inability to pass the ICAD lesion, and this can be considered an acceptable risk. Symptomatic intracranial hemorrhage was probably affected by low Alberta Stroke Program Early CT Score (ASPECTS) on the initial CT scan with a high NIHSS. Moreover, in 2 cases in this study, Enterprise stenting overcame the Wingspan stent's disadvantagesan inability to pass the stent due to severe stenosis and an inability to access the lesion site due to vessel tortuosity.

Although a major concern of intracranial stenting in AIS patients is the high rate of instant in-stent thrombosis right after stent deployment (58.8\% in this study) caused by insufficient antiplatelet premedication, low dose GP IIb-IIIa inhibitor administration solved this effectively and safely in this study. A previous study about low-dose IA tirofiban injection for instant re-occlusion by in situ thrombo-occlusion supports these results. ${ }^{32}$ However, although only 1 patient suffered from symptomatic intracranial hemorrhage in this study, care should be taken in patients who have received multiple coagulation-system-altering medications. Addition- ally, it should be noted that some patients in this series also received post-stenting adjunctive therapy like angioplasty and/or GP IIb-IIla inhibitor administration to achieve maximal recanalization results. So, the overall clinical outcomes cannot be solely attributed to stent placement, and rather should be interpreted within the context of the full course of therapy.

Our study has several limitations. First, the study design was retrospective with a small case series, and treatment decisions were not based on a standardized treatment protocol. Second, the evaluation of underlying ICAD is only based on angiographic findings. In fact, since there were 2 patients with arterial fibrillation, the possibility of embolic occlusion could not be completely ruled out. Third, there were no findings of restenosis of the stented segment on follow-up CT angiography, but this could not be confirmed because there was a lack of transfemoral catheter angiographic follow-up imaging after Enterprise stenting. So, in-stent restenosis cannot be ruled out, which is a major drawback after intracranial stenting despite the absence of recurrent ischemic symptoms during the follow-up periods. So, a large prospective study is necessary in patients with ischemic symptoms with underlying ICAD, which may affect the decision to utilize endovascular revascularization procedures for that condition.

\section{CONCLUSION}

The preliminary study reported herein provides evidence demonstrating the safety and efficacy of the Enterprise stent system for recanalization of ICAD. Further follow-up and more experience are also necessary to determine long-term results of intracranial steno-occlusive lesions treated with the Enterprise stent system.

\section{Fund}

None.

\section{Ethics Statement}

The Institutional Review Board at the Gangnam Severance Hospital approved this study. Informed consent was waived due to retrospective study design.

\section{Conflicts of Interest}

SHS has been the Editor-in-chief of the Neurointervention since 2022. No potential conflict of interest relevant to this 
article was reported.

\section{Author Contributions}

Concept and design: SK, KL, and SHS. Data collection: WSJ. Writing the article: WSJ. Final approval of the article: SHS. Overall responsibility: WSJ.

\section{ORCID}

Woo Sang Jung: https://orcid.org/0000-0002-0727-3744

Sam-Soo Kim: https://orcid.org/0000-0001-6725-8813

Kyung-Yul Lee: https://orcid.org/0000-0001-5585-7739

Sang Hyun Suh: https://orcid.org/0000-0002-7098-4901

\section{REFERENCES}

1. Wong LK. Global burden of intracranial atherosclerosis. Int J Stroke 2006;1:158-159

2. Arenillas JF. Intracranial atherosclerosis: current concepts. Stroke 2011;42(1 Suppl):S20-S23

3. Kasner SE. Natural history of symptomatic intracranial arterial stenosis. J Neuroimaging 2009;19 Suppl 1:20S-21S

4. Thijs VN, Albers GW. Symptomatic intracranial atherosclerosis: outcome of patients who fail antithrombotic therapy. Neurology 2000;55:490-497

5. Henkes H, Miloslavski E, Lowens S, Reinartz J, Liebig T, Kühne D. Treatment of intracranial atherosclerotic stenoses with balloon dilatation and self-expanding stent deployment (WingSpan). Neuroradiology 2005;47:222-228

6. Lee TH, Kim DH, Lee BH, Kim HJ, Choi CH, Park KP, et al. Preliminary results of endovascular stent-assisted angioplasty for symptomatic middle cerebral artery stenosis. AJNR Am J Neuroradio/ 2005;26:166-174

7. Weber W, Mayer TE, Henkes H, Kis B, Hamann GF, Schulte-Altedorneburg G, et al. Stent-angioplasty of intracranial vertebral and basilar artery stenoses in symptomatic patients. Eur J Radiol 2005:55:231-236

8. Zaidat OO, Klucznik R, Alexander MJ, Chaloupka J, Lutsep H, Barnwell S, et al.; NIH Multi-center Wingspan Intracranial Stent Registry Study Group. The NIH registry on use of the Wingspan stent for symptomatic 70-99\% intracranial arterial stenosis. Neurology 2008;70:1518-1524

9. Costalat V, Maldonado IL, Vendrell JF, Riquelme C, Machi P, Arteaga $C$, et al. Endovascular treatment of symptomatic intracranial stenosis with the Wingspan stent system and Gateway PTA balloon: a multicenter series of 60 patients with acute and midterm results. J Neurosurg 2011;115:686-693

10. Jiang WJ, Yu W, Du B, Gao F, Cui LY. Outcome of patients with $\geq 70 \%$ symptomatic intracranial stenosis after Wingspan stenting. Stroke 2011:42:1971-1975

11. Gandini R, Chiaravalloti A, Pampana E, Massari F, Morosetti D, Spano S, et al. Intracranial atheromatous disease treatment with the Wingspan stent system: evaluation of clinical, procedural outcome and restenosis rate in a single-center series of 21 consecutive patients with acute and mid-term results. Clin Neurol Neurosurg 2013;115:741-747

12. Durst CR, Geraghty SR, Southerland AM, Starke RM, Rembold $\mathrm{K}$, Malik S, et al. Stenting of symptomatic intracranial stenosis using balloon mounted coronary stents: a single center experience. J Neurointerv Surg 2015;7:245-249

13. Fujimoto M, Shobayashi Y, Takemoto K, Tateshima S, Viñuela F. Structural analysis for Wingspan stent in a perforator model. Interv Neuroradiol 2013;19:271-275

14. Zhao LB, Park S, Lee D, Lee DH, Suh DC. Mechanism of procedural failure related to wingspan. Neurointervention 2012;7:102108

15. Dumont TM, Natarajan SK, Eller JL, Mocco J, Kelly WH Jr, Snyder $\mathrm{KV}$, et al. Primary stenting for acute ischemic stroke using the Enterprise vascular reconstruction device: early results. J Neurointerv Surg 2014;6:363-372

16. Mocco J, Hanel RA, Sharma J, Hauck EF, Snyder KV, Natarajan SK, et al. Use of a vascular reconstruction device to salvage acute ischemic occlusions refractory to traditional endovascular recanalization methods. J Neurosurg 2010;112:557-562

17. Zaidat $\bigcirc O$, Yoo AJ, Khatri P, TomsickTA, von Kummer R, Saver JL, et al.; Cerebral Angiographic Revascularization Grading (CARG) Collaborators; STIR Revascularization working group; STIR Thrombolysis in Cerebral Infarction (TICI) Task Force. Recommendations on angiographic revascularization grading standards for acute ischemic stroke: a consensus statement. Stroke 2013;44:2650-2663

18. Sacco RL, Kargman DE, Gu Q, Zamanillo MC. Race-ethnicity and determinants of intracranial atherosclerotic cerebral infarction. The Northern Manhattan stroke study. Stroke 1995;26:14-20

19. Inzitari D, Hachinski VC, Taylor DW, Barnett HJ. Racial differences in the anterior circulation in cerebrovascular disease. How much can be explained by risk factors? Arch Neurol 1990;47:1080-1084

20. Lee SJ, Cho SJ, Moon HS, Shon YM, Lee KH, Kim DI, et al. Combined extracranial and intracranial atherosclerosis in Korean patients. Arch Neurol 2003;60:1561-1564

21. Suh DC, Lee SH, Kim KR, Park ST, Lim SM, Kim SJ, et al. Pattern of 
atherosclerotic carotid stenosis in Korean patients with stroke: different involvement of intracranial versus extracranial vessels. AJNR Am J Neuroradiol 2003;24:239-244

22. Park KY, Chung CS, Lee KH, Kim GM, Kim YB, Oh K. Prevalence and risk factors of intracranial atherosclerosis in an asymptomatic Korean population. J Clin Neurol 2006;2:29-33

23. Chimowitz MI, Lynn MJ, Howlett-Smith H, Stern BJ, Hertzberg VS, Frankel MR, et al.; Warfarin-Aspirin Symptomatic Intracranial Disease Trial Investigators. Comparison of warfarin and aspirin for symptomatic intracranial arterial stenosis. N Engl J Med 2005;352:1305-1316

24. EC/IC Bypass Study Group. Failure of extracranial-intracranial arterial bypass to reduce the risk of ischemic stroke. Results of an international randomized trial. N Engl J Med 1985;313:11911200

25. Kim DJ. Intracranial stenting; the current landscape. Neurointervention 2021;16:2-5

26. Chimowitz MI, Lynn MJ, Derdeyn CP, Turan TN, Fiorella D, Lane $B F$, et al.; SAMMPRIS Trial Investigators. Stenting versus aggressive medical therapy for intracranial arterial stenosis. N Engl J Med 2011;365:993-1003 Erratum in: N Engl J Med 2012;367:93

27. Levy El, Turk AS, Albuquerque FC, Niemann DB, Aagaard-Kienitz
$B$, Pride $L$, et al. Wingspan in-stent restenosis and thrombosis: incidence, clinical presentation, and management. Neurosurgery 2007;61:644-650; discussion 650-651

28. Turk AS, Levy El, Albuquerque FC, Pride GL Jr, Woo H, Welch BG, et al. Influence of patient age and stenosis location on wingspan in-stent restenosis. AJNR Am J Neuroradio/ 2008;29:23-27

29. Albuquerque FC, Levy El, Turk AS, Niemann DB, Aagaard-Kienitz $B$, Pride GL Jr, et al. Angiographic patterns of Wingspan in-stent restenosis. Neurosurgery 2008;63:23-27; discussion 27-28

30. Vajda Z, Schmid E, Güthe T, Klötzsch C, Lindner A, Niehaus L, et al. The modified Bose method for the endovascular treatment of intracranial atherosclerotic arterial stenoses using the Enterprise stent. Neurosurgery 2012;70:91-101; discussion 101

31. Kim JK, Ahn JY, Lee BH, Chung YS, Chung SS, Kim OJ, et al. Elective stenting for symptomatic middle cerebral artery stenosis presenting as transient ischaemic deficits or stroke attacks: short term arteriographical and clinical outcome. J Neurol Neurosurg Psychiatry 2004;75:847-851

32. Kang DH, Kim YW, Hwang YH, Park SP, Kim YS, Baik SK. Instant reocclusion following mechanical thrombectomy of in situ thromboocclusion and the role of low-dose intra-arterial tirofiban. Cerebrovasc Dis 2014;37:350-355 